\title{
Cytodiagonosis of Cystic Nodular Hidradenoma Presenting as Thigh Mass
}

Prakriti Shukla*, Shalini Tripathi, Medha Yadav

Department of Pathology, Hind Institute of Medical Sciences, Barabanki, Uttar Pradesh, India

*Corresponding author: Prakriti Shukla, Department of Pathology, Hind Institute of Medical Sciences, Barabanki, Uttar Pradesh, India, Tel: +919621664514; E-mail: prakritishukla24@gmail.com

Received date: Nov 12, 2018; Accepted date: Nov 26, 2018; Published date: Nov 30, 2018

Copyright: $@ 2018$ Prakriti Shukla. This is an open-access article distributed under the terms of the Creative Commons Attribution License, which permits unrestricted use, distribution, and reproduction in any medium, provided the original author and source are credited.

\begin{abstract}
Nodular hidradenoma is an unusual benign adnexal tumor arising from the excretory duct of sweat glands. It usually occurs in elderly females and commonly involves the scalp, neck, trunk, and extremities. Although it is diagnosed on histopathology, knowledge of cytological features can help in their early detection. Moreover, longstanding undiagnosed cases can rarely turn into malignancy. Thus, it is essential to identify these tumors in advance to treat them timely. Therefore, we herein describe certain salient cytological features of nodular hidradenoma that occurred as a large nodular soft tissue mass on the right thigh of an elderly female.
\end{abstract}

Keywords: Nodular Hidradenoma; Cystic swelling; Thigh; Clear cell

\section{Introduction}

Nodular Hidradenoma $(\mathrm{NH})$ is a rare benign adnexal tumor of sweat gland origin with distinct morphology. It was first described by Liu in 1949 as clear cell papillary carcinoma of the skin [1]. It is a solitary, slow growing, well circumscribed and freely mobile dermal tumor usually seen in middle-aged females. It mostly occurs on the scalp, neck, trunk, and extremities

Cytological features of nodular hidradenoma are less known and often misdiagnosed as commonly known other benign or malignant lesions. Herein, we describe the salient cytomorphological features of cystic nodular hidradenoma for its early detection and management.

\section{Case Report}

A 50-year-old female presented with a slow growing, painless, nodular swelling on the back of right thigh for six months. Physical examination revealed a solitary, non-tender, soft to a firm nodule that was $6 \times 5 \mathrm{~cm}$ in size. All hematological and biochemical parameters were within normal limits. Fine needle aspiration cytology was advised with a clinical impression of soft tissue neoplasm. Cytosmears were richly cellular and revealed occasional clusters and many singly lying dual population of cells, one comprising of small round cells with clear cytoplasm and other polygonal cells with basophilic cytoplasm on a hemorrhagic background (Figure 1). Occasional cells with signet ring morphology were also observed. The background showed few cyst macrophages, neutrophils, bare nuclei, and mucinous material. Thus, a cytological impression of the benign adnexal tumor was suggested and excision biopsy was advised.

On gross examination, a gray-brown skin covered nodular soft tissue piece measuring $6.5 \times 5 \times 4 \mathrm{~cm}$ was noted (Figure 2). Cut surface showed solid-cystic areas with few papillary projections. Microscopy revealed a well-circumscribed dermal tumor with the unremarkable epidermis. A tumor was arranged in lobules and ducts with lumen showing PAS-positive eosinophilic secretions (Figure 3). At places, tumor cells were arranged in a papillaroid configuration. The individual tumor cells were uniform and round with bland nuclei, inconspicuous nucleoli and moderately eosinophilic to clear cytoplasm with distinct cell outline (Figure 4). No cytological atypia, mitosis or necrosis was evident. Thus, a histopathological diagnosis of nodular hidradenoma was rendered. The patient was put on antibiotics and analgesics. Follow-up of the patient revealed no significant complaints [2-4].

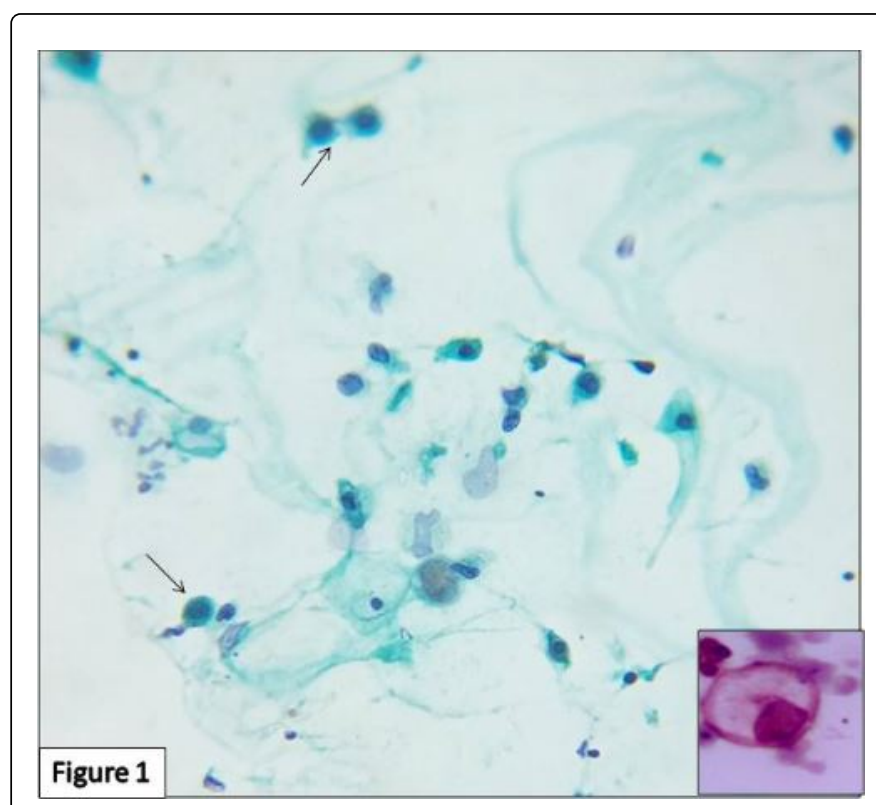

Figure 1: Cytosmears showing basaloid cells with several macrophages and neutrophils and occasional signet ring like cells (inset) (100X, PAP)

\section{Discussion}

Nodular Hidradenoma also known as Ecrine acrospiroma or solidcystic hidradenoma is a benign tumor with clear cell morphology. Limited reports on its cytological features have been published. Most cases are either misinterpreted or remain undiagnosed on cytology. 
Citation: Shukla P, Tripathi S, Yadav M (2019) Cytodiagonosis of Cystic Nodular Hidradenoma Presenting as Thigh Mass. Dermatol Case Rep 3: 144.

Page 2 of 2

Long-standing undiagnosed cases can sometimes turn into malignancy. This case report highlights salient cytomorphological features of nodular hidradenoma that would aid in its early diagnosis on Fine Needle Aspiration Cytology (FNAC) and prompt management in the form of wide local excision.

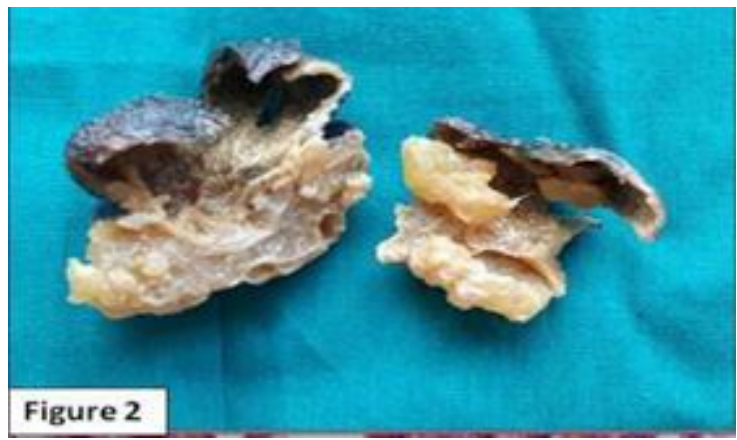

Figure 2: Gross specimen showing solid-cystic areas.

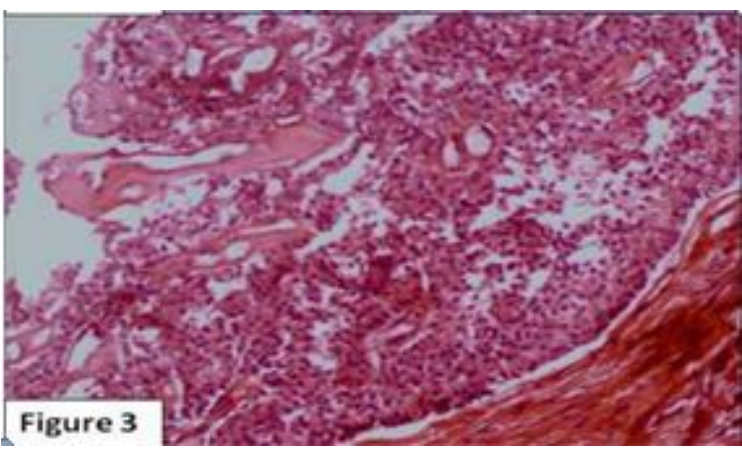

Figure 3: Photomicrograph showing a well-circumscribed dermal tumor with papillaroid configuration (100X, $\mathrm{H}$ and $\mathrm{E}$ ).

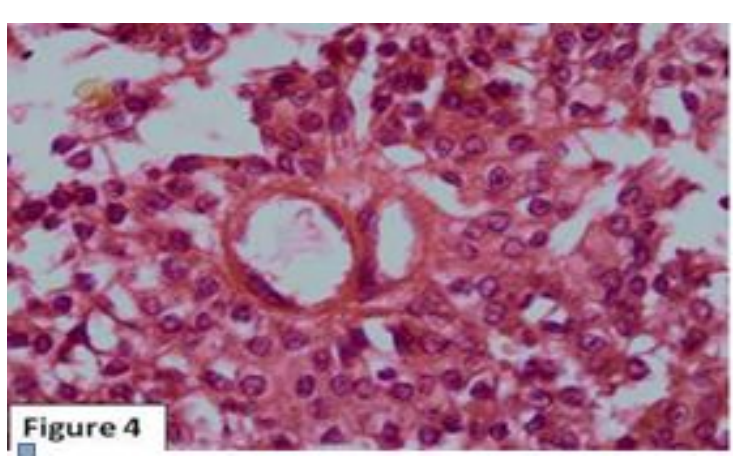

Figure 4: Photomicrograph showing individual tumor cells with uniform and round with bland nuclei (400X, $\mathrm{H}$ and $\mathrm{E})$.
Cytosmears are highly cellular and reveal clusters and singly lying polyhedral cells with eosinophilic to clear cytoplasm and round nuclei [5]. Few of the cells may appear basaloid while others may show signet ring-like or squamoid morphology. The background shows extracellular hyaline amorphous material. Histiocytes, fibrocytes, pigmented macrophages, foam cells, and naked nuclei may be seen [6]. In our case, smears revealed two types of cells-basophilic and clear cells with few showing signet ring-like morphologies.

Marked morphological variability of different cell types may be noted. However, based on the number of different cell types, cytopathologists must be aware of its resemblance to other common tumors like metastatic renal cell carcinoma, squamous cell carcinoma, and signet-ring adenocarcinoma. Thus, knowledge of cytologic features of nodular hidradenoma is essential for its accurate diagnosis.

\section{References}

1. Bagga PK, Shahi M, Nahajan NC (2009) Clear cell hidradenoma-A case report. The Internet Journal Of Pathology 8: 22.

2. Grampurohit VU, Dinesh U, Rao R (2011) Nodular hidradenoma of male breast: Cytohistological correlation. J Cytol 28: 235-7.

3. Nasit JG, Dhruva G (2014) Nodular hidradenoma of the scalp: A cytomorphological evaluation on fine needle aspiration cytology. Indian J Dermatol Venereol Leprol 80: 569-72.

4. Santosh T, Patro MK, Behera JK, Dash AK (2016) Nodular hidradenoma: A rare cytological diagnosis. J Cancer Sci Ther 8: 048-049.

5. Kumar N, Verma K (1996) Clear cell hidradenoma simulating breast carcinoma: a diagnostic FNA breast. Diagn cytopathol 15: 70-72.

6. Agarwal S, Agarwal K, Kathuria P, Jain M, Chauhan DS, et al. (2006) Cytomorphological features of nodular hidradenoma highlighting eccrine differentiation: A case report. Indian J Pathol Microbiol 49: 411-413. 